\title{
Analisa Pola Frekuensi Keranjang Belanja Dengan Perbandingan Algoritma Fp-Growth (Frequent Pattern Growth) Dan Eclat Pada Minimarket
}

\author{
Krisna Nata Wijaya ${ }^{1}$, Reza Firsandaya Malik $^{2}$, Siti Nurmaini ${ }^{3}$ \\ 1,2,3 Magister Ilmu Komputer, Fakultas Ilmu Komputer Unsri, Palembang \\ ${ }^{1}$ krisna.auxilia@gmail.com, ${ }^{2}$ rezafm@ unsri.ac.id, ${ }^{3}$ siti_nurmaini@unsri.ac.id
}

\begin{abstract}
Abstrak
Dalam kegiatan transaksi jual beli di minimarket ataupun toko pemilik harus mengerti apa yang diinginkan komsumen dalam memberikan kenyaman berbelanja, terutama kemudahan dalam pemilihan barang yang disesuaikan dengan tata letak atau penempatan barang. Dengan menerapkan association rule pada data transaksi akan memudahkan pemilik dalam mengelolah informasi penjualan dan mencari itemset. Oleh karena itu, penelitian ini melakukan analisis pola data transaksi penjualan dengan menerapkan metode asosiasi pada data mining. Data dipersiapkan dengan melalui proses seleksi data, pembersihan data dan ditransformasi ke bentuk yang dapat diolah oleh sistem. Selanjutnya data diolah menggunakan algoritma FPGrowth dan Eclat dengan melakukan perbandingan hasil dari algoritma berupa aturan asosiasi yang terbentuk dan kecepatan waktu proses dari masing-masing algoritma dengan minimum support dan confidence sebesar $0.01 \%$ untuk menentukan jumlah aturan yang kuat pada tabel dan grafik sebagai bahan pengambil keputusan yang ditunjukan untuk frekuensi keranjang belanja.
\end{abstract}

Kata kunci-aturan asosiasi, Algoritma Frequent Pattern Growth, Eclat

\begin{abstract}
In buying and selling transactions at minimarkets or stores, the owner must understand what the consumer wants in order to provide comfort in shopping, especially the ease in selecting goods that are adjusted to the layout or placement of the goods. By applying the association rule to transaction data, it will make it easier for owners to manage sales information and search for itemsets. Therefore, this study analyzes sales transaction data patterns by applying the association method to data mining. Data is prepared by going through a data selection process, data cleaning and transformed into a form that can be processed by the system. Furthermore, the data is processed using the FP-Growth and Eclat algorithms by comparing the results of the algorithm in the form of association rules that are formed and the processing time speed of each algorithm with a minimum support and confidence of $0.01 \%$ to determine the number of strong rules in tables and graphs as material. designated decision maker for shopping cart frequency.
\end{abstract}

Keywords-association rules, Frequent Pattern Growth Algorithm, Eclat 


\section{PENDAHULUAN}

Dalam persaingan di dunia bisnis, khususnya di industri retail yang menjual kebutuhan sehari-hari menuntut para pengembang untuk menemukan suatu strategi apa yang sebenarnya diinginkan oleh konsumennya terutama dalamkenyamanan memberikan kemudahan memilih barang, potongan harga bahkan promo barang belanjaan, contoh strategi peletakan posisi barang didalam rak yang disesuaikan dengan karakteristik barang atau kesamaan jenis. Penerapan data mining dalam proses mencari pola atau informasi menarik dalam data dengan menggunakan metode tertentu [1]. Salah satu metode yang seringkali digunakan dalam teknologi data mining adalah metode asosiasi atau association rule mining.

Didalam bidang usaha metode association rule mining ini dikenal dengan istilah Market basket Analysis (MBA). MBA merupakan sebuah analisis terhadap kebiasaan konsumen berbelanja untuk menemukan asosiasi dan korelasi diantara berbagai macam items yang akan dibeli. Spesifiknya MBA bertujuan untuk mengetahui items apa saja yang sering dibeli bersamaan [2], [3]. Items yang di maksud adalah berbagai macam produk atau barang,Pada penelitian sebelumnya telah ada upaya dalam menentukan pola peminjaman buku di perpusatakaan universitas lancar kuning dengan menganalisa perbandingan algoritma Apriori dengan Eclat sebagai pengambil keputusan [4], untuk mengambil sebuah keputusan bisnis dari metode asosiasi tersebut dilakukan sebuah perbandigan algoritma Fp-Growth dan Eclat yang berdasarkan dari himpunan data untuk membantu dalam membentuk kombinasi barang kemudian dilakukan pengujian apakah kombinasi tersebut memenuhi nilai dan membantu tata letak barang dalam rak berdasarkan kecenderungan konsumen

Fp-Growth adalah salah satu alternatif algoritma yang dapat digunakan untuk menentukan data yang sering muncul (frequent itemset) dalam sebuah kumpulan data [5]. Algoritma FP-Growth jika dibandingkan dengan algoritma lain dalam metode asosiasi seperti algoritma apriori, memiliki waktu kerja yang lebih cepat dalam menemukan frequent itemset. Sedangkan Algoritma Eclat pada dasarnya adalah pencarian algoritma depth-first menggunakan persimpangan yang ditetapkan. Eclat menggunakan basis data dengan tata letak vertical [6].

\section{METODE PENELITIAN}

\subsection{Metode Pengembangan}

Pada paper ini, metode yang diterapkan adalah Agile Sofware Development (ASD) berjangka pendek, yang memerlukan adaptasi cepat dan pengembangan terhadap perubahan apapun. Penelitian dilakukan dengan mengumpulkan data dan studi awal atau kepustakaan demi memahami penerapan data mining tentang teori-teori yang berkaitan dengan data mining, algoritma FP-Growth dan Eclat. Data yang diperoleh digunakan sebagai analisa perbandingan untuk kebutuhan proses asosiasi data dalam menarik kesimpulan dengan tetap memperhatikan tahapan dari metode tersebut, seperti pada gambar $1[6]$.

Wijaya, et al (Analisa Pola Frekuensi Keranjang Belanja Dengan Perbandingan Algoritma Fp-Growth (Frequent Pattern Growth) dan Eclat pada Minimarket) 


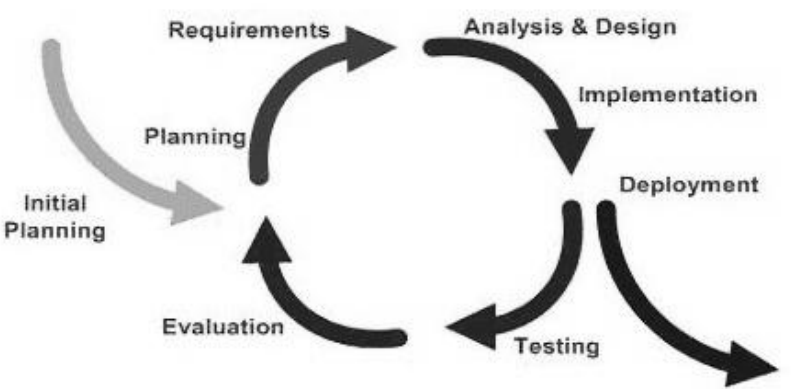

Gambar 1. Tahapan Agile Software Development

\subsubsection{Konsep Penelitian}

Pada gambar 2 menunjukan kerangka Metode penelitian sebagai berikut.

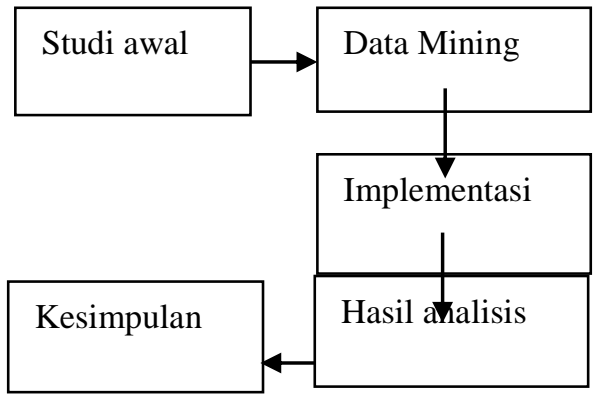

Gambar 2. Metodelogi Penelitian

1. Studi Awal

Pada tahap ini bertujuan untuk merumuskan permasalahan yang akan dibahas antara lain: mempelajari ruang lingkup masalah, literature dan analisis data.

2. Data Mining

Terlebih dahulu mengidentifikasi masalah dan mendeskripsikannya untuk memperoleh solusi. Selanjutnya menggunakan teknik data mining dengan menerapkan Knowledge Discorvery in Database guna melakukan seleksi data, pembersihan data dan transformasi data agar data bisa diolah saat penerapan algoritma Fp-Growth dan Eclat untuk mendapatkan hasil yang diinginkan

3. Implementasi

untuk memudahkan hasil analisa, Membuat perbandingan hasil dari penerapan algoritma yang digunakan dalam bentuk tabel dan grafik.

4. Hasil Analisa

Analisis akhir dari perhitungan dengan algoritma Fp-Growth dan Eclat menghasilkan aturan asosiasi keputusan yang digunakan untuk penentuan pola dan frekuensi pembelian.

5. Kesimpulan

Aturan asosiasi yang terbentuk diurutkan dalam tabel dan dapat digunakan sebagai sumber pengetahuan baru atau keputusan bisnis.

\subsection{Landasan Teori}

2.2.1Analisa Pola Frekuensi Tinggi

Association rule atau metode asosiasi data mining adalah teknik untuk menemukan aturan asosiatif pada data mining suatu kombinasi item, contoh mengetahui besarnya

Wijaya, et al (Analisa Pola Frekuensi Keranjang Belanja Dengan Perbandingan Algoritma Fp-Growth (Frequent Pattern Growth) dan Eclat pada Minimarket) 
kemungkinan pelanggan membeli suatu barang bersamaan dengan barang lain yang saling bersangkutan, ataupun merancang untuk kombinasi barang tertentu. Istilah lain dari analisis asosiasi lebih dikenal dengan Market Basket Analysis (MBA) [3][7]. MBA merupakan salah satu teknik mendasar dari Data mining yaitu analisis pola frekuensi tinggi (frequent pattern mining), dengan menggunakan dua parameter, Support adalah persentasi kombinasi item di dalam basis data dan confidance adalah kuatnya hubungan antar item dalam asosiation rule yang terbentuk. Selain itu Aturan asosiasi juga digunakan sebagai patokan untuk menemukan nilai-nilai yang memenuhi syarat minimum support dan confidence pada suatu aturan.

$$
\operatorname{Support}(A)=\frac{\sum \text { Transaksi Mengandung A }}{\sum \text { Transaksi }} \times 100 \%
$$

Sementara nilai Support dari-2 item diperoleh dari rumus berikut:

$$
\begin{gathered}
\text { Support }(A, B)=P(A \cap B) \\
\operatorname{Support}(A, B)=\frac{\sum \text { Transaksi Mengandung } A \& B}{\sum \text { Transaksi }} \times 100 \%
\end{gathered}
$$

Nilai dari Support 'A' dan 'B' diperoleh dari pembagian antara jumlah transaksi yang mengandung ' $A$ ' dan ' $B$ ' dengan total transaksi yang akhirnya dikali degan 100 Persen, Sedangkan untuk mencari nilai minimum confidence dengan rumus berikut:

$$
=P(A \mid B)=\frac{\begin{array}{c}
\text { Confidence }(A \rightarrow B) \\
\text { Transaksi Mengandung } A \& B
\end{array}}{\sum \text { Transaksi }} \times 100 \%
$$

Nilai confidence atau Kepastian $(\mathrm{A} \rightarrow \mathrm{B})$ Diperoleh dengan membagi jumlah Transaksi yang mengandung ' $A$ ' dan ' $B$ ' dengan Total Transaksi yang dikali dengan 100 persen.

\subsubsection{Konsep Frequent Pattern Growth (FP-Growth)}

Algoritma Fp-Growth merupakan pengembangan dari algoritma Apriori karena kekurangan yang ada pada algoritma Apriori diperbaiki oleh algoritma Fp-Growth [8]. FpGrowth merupakan salah satu algoritma yang dapat digunakan untuk menentukan himpunan data yang paling sering muncul (Frequent itemset) dalam sebuah kumpulan data.Karakteristik algoritma Fp-Growth adalah struktur dari data digunakan adalah tree atau disebut dengan $F p$ tree. Dengan menggunakan $F p$-Tree, algoritma ini dapat langsung mengekstrak frequent itemset dari Fp-Tree

FP-Tree merupakan struktur penyimpanan data yang dimampatkan. FP-tree dibangun dengan memetakansetiap data transaksi ke dalam setiap lintasan tertentu dalam FP-tree. Karena dalam setiap transaksi yang dipetakan, mungkin ada transaksi yang memiliki item yang sama, maka lintasannya memungkinkan untuk saling menimpa. Semakin banyak data transaksi yang memiliki item yang sama, maka proses pemanpatan dengan struktur data FP-tree semakin efektif.Kelebihan dari FP-tree adalah hanya memerlukan dua kali pemindaian data transaksi yang terbukti sangat efisien [9][10].

Metode FP-Growth dapat dibagi menjadi 3 tahapan yaitu:

1. Tahap pembangkitan conditionalpattern base, merupakan sub database yang berisi prefix path dan suffix pattern yang di dapat dari dari FP tree yang telah di bentuk.

Wijaya, et al (Analisa Pola Frekuensi Keranjang Belanja Dengan Perbandingan Algoritma Fp-Growth (Frequent Pattern Growth) dan Eclat pada Minimarket) 
2. Tahap pembangkitan conditional Fp-Tree, support count dari setiap item pada setiap conditional pattern base di jumlahkan, kemudian setiap item yang memiliki jumlah support lebih besar atau sama dengan nilai minimum support yang akan di bangkitkan.

3. Tahap pencarian frequent itemset, jika conditional Fp-tree adalah lintasan tunggal (single Path), maka bias di dapat frequent pattern dari kombinasi item untuk setiap conditional Fptree, dan jikan bukan lintasan tunggal, maka lakukan pembangkitan secara rekursif.

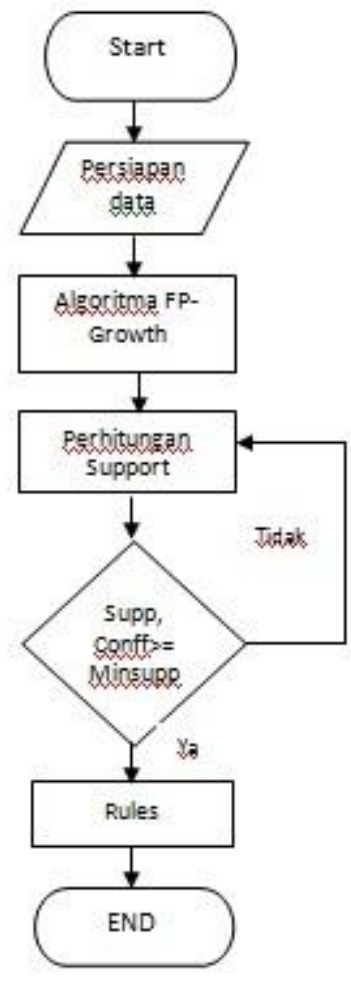

Gambar 3. Flowchart Frequent Pattern Growth

Pada gambar 3, merupakan diagram alur yang digunakan dalam menerapkan FP-Growth, antara lain melakukan persiapan data dengan memindai data transaksi penjualan memilah atribut dan mengilangkan data yang bersifat redudansi. Proses selanjutnya melakukan perhitungan Support dan confidence untuk mengasilkan aturan dari algoritma FP-Growth.

\subsubsection{Konsep Eclat (Equivalence Class Transformation)}

Algoritma Eclat adalah salah satu algoritma yang disuslkan M. Zaki dalam metode Association rules yang memiliki waktu pencarian frequentitemset lebih cepat di banding dengan Algoritma Apriori dengan teknik pendekatan BDF (Breath deep First) dengan melakukan scan pada database sebanyak 3(tiga) kali yang mentransformasikan tabel yang dapat mengurangi proses input dan output.

Eclat merupakan algoritma yang diterapkan untuk menemukan itemset yang sering muncul pada basis data. Algoritma ini pada dasarnya melakukan pencarian secara Depth First Search (DFS) dengan tata letak vertikal dan jika database berbentuk horizontal terlebih dahulu dikonversi menjadi vertikal [8]. Menurut Adita et al.,n.d Eclat di bagi menjadi 3 tahapan yaitu:

1. Inisialisasi yaitu konstruksi perhitungan global untuk frequent 2-itemset.

2. Tahap Transformasi, yaitu membagi Frequent 2-itemset dan menjadwalkan partisi tersebut di prosessor, yang selanjutnya melakukan transformasi vertikal pada databse.

3. Tahap Asynchronous, adalah pembentukan frequent k-itemset sesuai kebutuhan atau tujuan yang ingin di capai.

Wijaya, et al (Analisa Pola Frekuensi Keranjang Belanja Dengan Perbandingan Algoritma Fp-Growth (Frequent Pattern Growth) dan Eclat pada Minimarket) 
Untuk mengasilkan aturan asosiasi Eclat sistem dimodelkan dengan menggunakan diagram alur (Flowchart) pada gambar 4, prinsip kerjanya untuk perhitungan Eclat Nilai MinnSupp harus memenuhi dan menghailkan Itemset yang kemudian menerapkan MinnConf untuk menghasilkan aturan asosiasi Eclat.

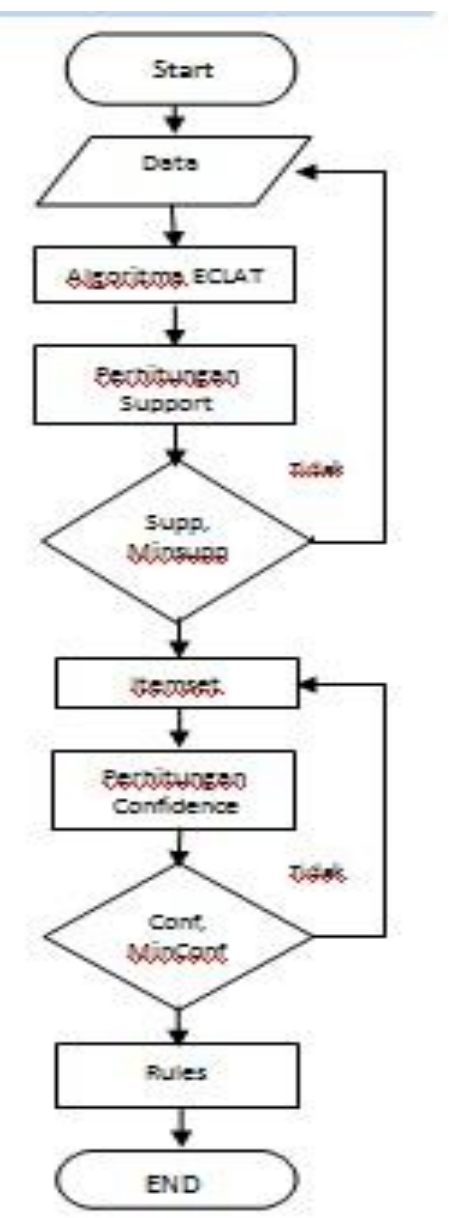

Gambar 4. Flowchart Eclat

\section{HASIL DAN PEMBAHASAN}

Dengan penerapan semua data transaksi yang telah dilakukan proses data cleaning atau pembersihan data, guna menghilangkan missing value dan sejumlah data yang mengandung redundant. Untuk mendapatkan hasil pola pembelian dan mengetahui perbandingan hasil dari algoritma Fp-growth dan Eclat dengan menggunakan RapidMiner dan RStudio sebagai pendukung keputusan. 


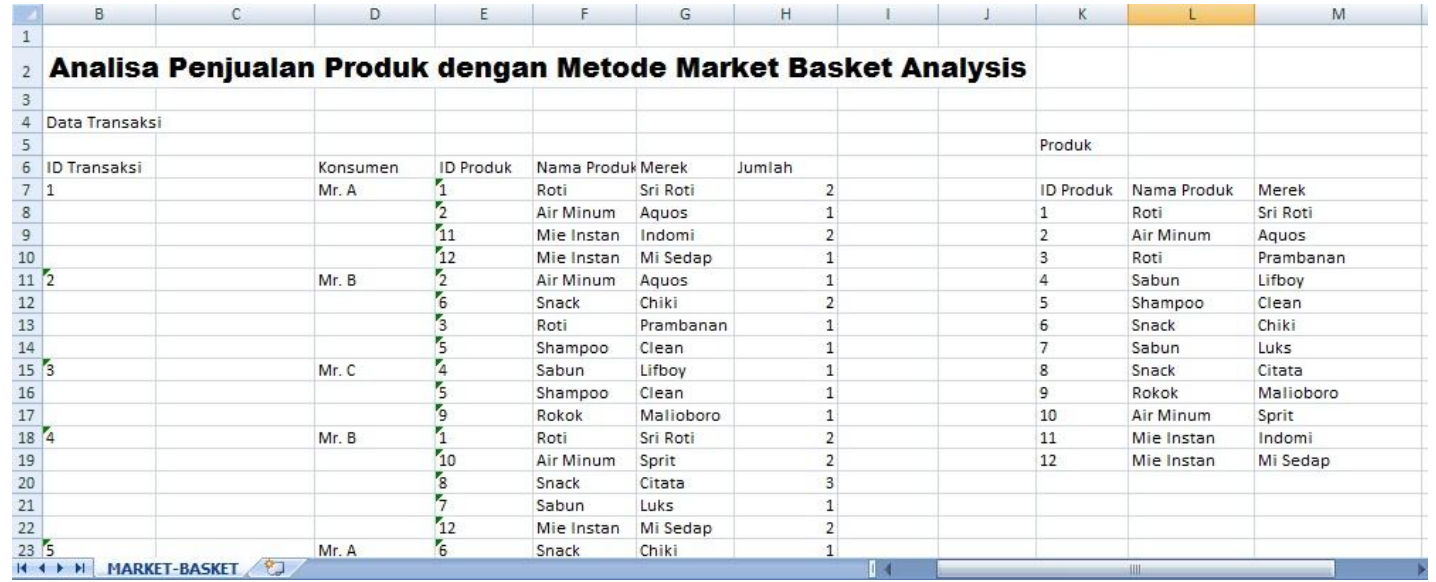

Gambar 5. Analisa Penjualan MBA

Database asal atau disebut data asli dari transaski pada gambar 5 merupakan data yang akan digunakan dalam penelitian. Metode MBA tidak akan melakukan seleksi atribut seperti ID_Transaksi, Nama_Barang serta menghilangkan Noise pada tabel dengan melakukan teknik Normalisasi agar bisa diterapkan pada Algoritma FP-Growth dan Eclat.

1. Mining Fp-Growth

Proses pengujian rule mining yang pertama menggunakan rapidminer dengan menetapkan nilai minimum support sebesar $0.01 \%$ untuk proses frequent itemset menghasilkan 155 dengan kombinasi yang terbentuk mulai dari 2 sampai 4 barang, yaitu 2 itemset berjumlah 139, 3 itemset berjumlah 15, dan 4 itemset berjumlah sebanyak 1 .

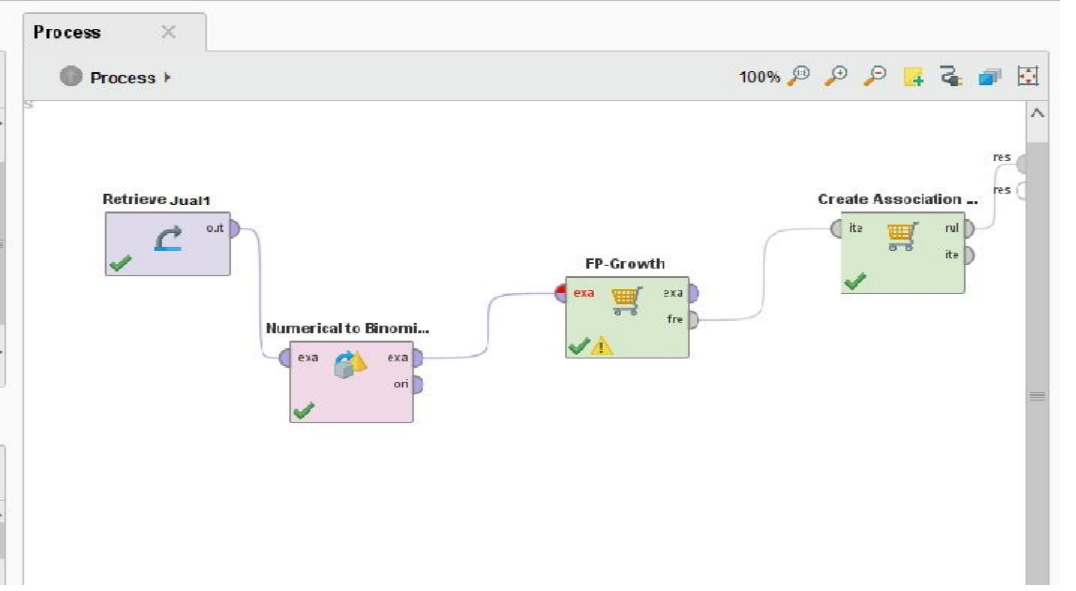

Gambar 6. Bangun Fp-Growth Import Data

Proses import data yang uji Jual1.xls yang selanjutnya digunakan untuk menghubungkan Fp-Growth ke bagian pertama serta create association rule ke bagian kedua dengan menetapkan nilai support dan confidence.

Tahap berikutnya guna menghasilkan aturan asosiasi nilai harus memenuhi nilai minimum support dan confidence yang ditetapkan. Nilai confidence yang diujikan sebesar 1.0.

Tabel 1. Hasil Aturan Mining Fp-Growth

\begin{tabular}{|c|l|c|c|}
\hline No. & \multicolumn{1}{|c|}{ Aturan } & Support & Confi \\
\hline 1. & $\begin{array}{l}\text { Jika membeli tepung segitiga biru 1kg, Maka membeli } \\
\text { bimoli refill 1kg }\end{array}$ & 0.014 & 1.0 \\
\hline 2. & Jika membeli beras raja platinum 10kg, Maka membeli & 0.010 & 1.0 \\
\hline
\end{tabular}

Wijaya, et al (Analisa Pola Frekuensi Keranjang Belanja Dengan Perbandingan Algoritma Fp-Growth (Frequent Pattern Growth) dan Eclat pada Minimarket) 


\begin{tabular}{|c|c|c|c|}
\hline & indomie goreng $40 \times 85 \mathrm{gr}$ & & \\
\hline 3. & $\begin{array}{l}\text { Jika membeli indomie goreng } 40 x 85 \mathrm{gr} \text {, tepung segitiga } \\
\text { biru } 1 \mathrm{~kg} \text {, Maka membeli Abc kecap manis } 135 \mathrm{ml}\end{array}$ & 0.013 & 1.0 \\
\hline 4 & $\begin{array}{l}\text { Jika membeli gulaku } 1 \mathrm{~kg} \text {, tea sari wangi } 25 \mathrm{pcs} \text {, Maka } \\
\text { membeli kopi abc } 500 \mathrm{gr}\end{array}$ & 0.010 & 1.0 \\
\hline 5. & $\begin{array}{l}\text { Jika membeli supermie kuah 40x70gr, indomie goreng } \\
\text { 40x85gr, Maka membeli Abc kecap manis } 135 \mathrm{ml}\end{array}$ & 0.010 & 1.0 \\
\hline 6. & $\begin{array}{l}\text { Jika membeli Abc kecap manis } 135 \mathrm{ml} \text {, indomie goreng } \\
40 x 85 \mathrm{gr} \text {, maka membeli tepung segitiga biru } 1 \mathrm{~kg}\end{array}$ & 0.010 & 1.0 \\
\hline 7. & $\begin{array}{l}\text { Jika membeli indomie goreng } 40 \times 85 \mathrm{gr} \text {, bimoli refill } \\
1 \mathrm{~kg} \text {,tepung segitiga biru } 1 \mathrm{~kg} \text {, maka membeli supermie } \\
\text { kuah 40x70gr }\end{array}$ & 0.010 & 1.0 \\
\hline 8. & $\begin{array}{l}\text { Jika membeli supermie kuah 40x70gr, tepung terigu } \\
\text { sgita biru } 1 \mathrm{~kg} \text {, indomie goreng 40x } 85 \mathrm{gr} \text {, } \\
\text { Maka membeli Abc kecap manis } 135 \mathrm{ml} \text {. }\end{array}$ & 0.010 & 1.0 \\
\hline
\end{tabular}

Sedangkan pada uji coba minsupp $0.01 \%$ dan minconfi sebesar 0.85 yang kedua menghasilkan 19 rules yang terbentuk dalam waktu proses 57 detik.

2. Mining Eclat

Untuk pengujian nilai support dan confidence pada algoritma éclat di lakukan dengan Rstudio dengan menetapkan nilai minimum support yang sama pada pengujian sebelumnya sebesar $0.01 \%$ menghasilkan frequent itemset sebanyak 155 dengan kombinasi 2 sampai 4 barang yaitu, 2 kombinasi sebanyak 140, 3 kombinasi sebanyak 14 dan 4 kombinasi sebanyak 1

Untuk menghasilkan aturan, input nilai confidence yang sebanding dengan algoritma Fpgrowth sebesar 1.0 yang menghasilkan aturan sebagai berikut:

Tabel 2. Hasil Aturan Mining Eclat.

\begin{tabular}{|c|l|c|c|}
\hline No. & \multicolumn{1}{|c|}{ Aturan } & Support & Confi \\
\hline 1. & $\begin{array}{l}\text { Jika membeli beras raja platinum 10kg, Maka } \\
\text { membeli indomie goreng 40x85gr }\end{array}$ & 0.013 & 1.0 \\
\hline 2. & $\begin{array}{l}\text { Jika membeli tepung segitiga biru 1kg, Maka } \\
\text { membeli bimoli refill 1kg }\end{array}$ & 0.010 & 1.0 \\
\hline 3. & $\begin{array}{l}\text { Jika membeli beras raja platinum 10kg, indomie } \\
\text { goring 40x85gr, Maka membeli abc kecap manis } \\
\text { 135ml }\end{array}$ & 0.013 & 1.0 \\
\hline 5 & $\begin{array}{l}\text { Jika membeli kopi abc 500gr, tea sari wangi 25pcs, } \\
\text { Maka membeli gulaku 1kg }\end{array}$ & 0.010 & 1.0 \\
\hline 5. & $\begin{array}{l}\text { Jika membeli indomie goreng 40x85gr, supermie } \\
\text { kuah 40x70gr, tepung segitiga biru 1kg, Maka } \\
\text { membeli bimoli refill 1kg }\end{array}$ & $\begin{array}{l}\text { Jika membeli tepung segitiga biru 1kg, Abc kecap } \\
\text { manis 135ml, Maka membeli indomie goreng } \\
\text { 40x85gr }\end{array}$ & 0.010 \\
\hline 7. & $\begin{array}{l}\text { Jika membeli supermie kuah 40x70gr, tepung } \\
\text { segitiga biru 1kg, indomie goreng 40x85gr, Maka } \\
\text { membeli abc kecap manis 135ml }\end{array}$ & 0.010 \\
\hline 8. & $\begin{array}{l}\text { Jika membeli tepung segitiga biru 1kg, indomie } \\
\text { goreng 40x85gr, abc kecap manis 135ml, Maka } \\
\text { membeli bimoli refill 1kg }\end{array}$ & 1.0 \\
\hline
\end{tabular}

Pada uji coba yang kedua dengan minsupp $0.01 \%$ dan minconfi sebesar 0.85 yang sama menghasilkan 14 rules yang terbentuk dengan waktu proses 12 detik. 
3. Hasil Perbandingan Algoritma Fp-Growth dan Eclat

Untuk melihat hasil perbandingan kedua algoritma tersebut dapat dibuat pada tabel 3.:

Tabel 3. Hasil Perbandingan Algoritma Fp-growth dan Eclat

\begin{tabular}{|c|c|c|c|c|}
\hline Algoritma & Jumlah Rules & Waktuproses & MinSupp & Confi \\
\hline \multirow{2}{*}{$\begin{array}{c}\text { Fp- } \\
\text { Growth }\end{array}$} & 8 & $49 \mathrm{~s}$ & $0.01 \%$ & 1.0 \\
\cline { 2 - 5 } & 19 & $57 \mathrm{~s}$ & $0.01 \%$ & 0.85 \\
\hline \multirow{2}{*}{ Eclat } & 8 & $12 \mathrm{~s}$ & $0.01 \%$ & 1.0 \\
\cline { 2 - 5 } & 14 & $12 \mathrm{~s}$ & $0.01 \%$ & 0.85 \\
\hline
\end{tabular}

Untuk hasil pengujian Fp-growth dengan minimum support $0.01 \%$ dan minimum confidence 0.85 adalah 19 rules yang terbentuk dengan waktu proses 57 detik. Sedangkan pengujian Eclat dengan nilai minimum support dan confidence yang sama menghasilkan 14 rules dengan kecepatan proses 12 detik.

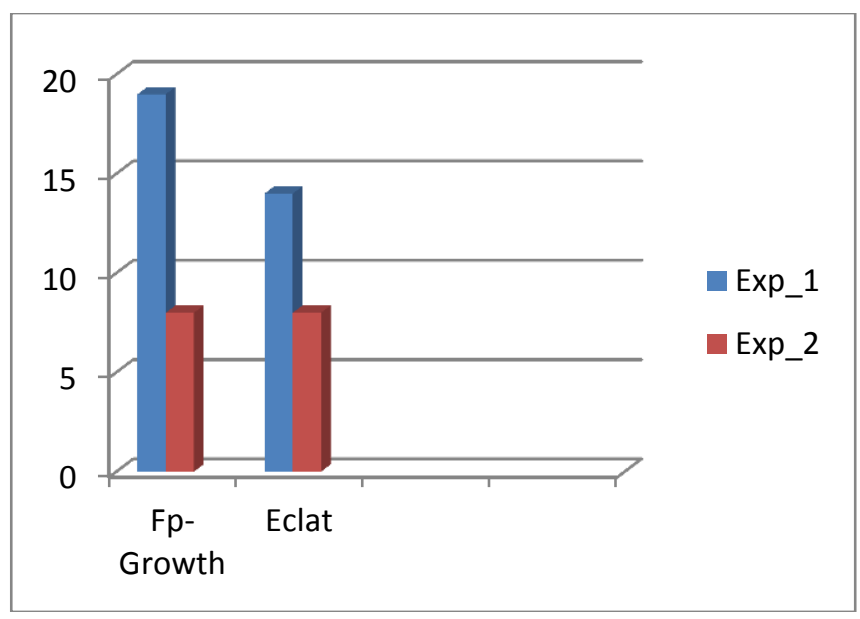

Gambar 6. Grafik Perbandingan Hasil Aturan Mining Fp-Growth dan Eclat

\section{KESIMPULAN}

Berdasarkan pada permasalahan dan tujuan penelitian dari hasil uji coba data transakasi dengan menerapkan algoritma Fp-Growth dan Eclat sebagai perbandingan dapat di simpulkan bahwa penerapkan metode association rule mining menghasilkan items yang sering dibeli secara bersamaan merupakan bahan sembako antara lain, kopi, terigu segitiga biru, Abc Kecap manis,beras raja platinum, tea indomie dan supermie kuah. Hasil uji perbandingan kedua algoritma yaitu Fp-growth dan Eclat menunjukan nilai support yang tinggi dan confidance menghasilkan sedikit rules yang lebih efesien atau aturan yang kuat dan waktu proses yang lebih cepat pada algoritma eclat.Dengan hasil ujisistem yang terdapat di konsep ini dapat digunakan sebagai pengelolah data penjualan yang begitu banyak dan menjadi suatu alternatif keputusan untuk melihat produk yang sering dibeli dan membantu pemilik dalam tata letak barang maupun kombinasi barang. 


\section{SARAN}

1. Pada masa mendatang perlu melakukan update basis data secara rutin guna memperbaruhi aturan mengenai frequensi keranjang belanja.

2. Agar lebih baik, penelitian ini dapat dikembangkan dengan perbandigan association rules data mining lainnya, serta menambah jenis item yang 1 tipe $\mathrm{p}[-;$;.,kelompok agar pola mining yang terbentuk lebih bervariasi dalam pengambilan keputusan.

\section{DAFTAR PUSTAKA}

[1] E. Taufiq Luthfi Kusrini, Kusrini, Luthfi, E. T., 2009, Algoritma Data Mining, Andi Offset, Yogyakarta.

[2] N. Wandi, R. A. Hendrawan, and A. Mukhlason, 2012, "Pengembangan Sistem Rekomendasi Penelusuran Buku dengan Penggalian Association Rule Menggunakan Algoritma Apriori," J. Tek. ITS, Vol. 1, pp. 1-5.

[3] E. S. Putra Christianto Purba, 2018, "Implementasi Algoritme Fp-Growth untuk Market Basket Analysis Dalam Menentukan Product Bundling," Appl. Data Min. Bus. Ind., No. February, pp. 175-191.

[4] L. Lisnawita and M. Devega, 2018. "Analisis Perbandingan Algoritma Apriori dan Algoritma Eclat Dalam Menentukan Pola Peminjaman Buku di Perpustakaan Universitas Lancang Kuning," INOVTEK Polbeng - Seri Inform., Vol. 3, No. 2, p. 118.

[5] G. Gunadi and D. I. Sensuse, 2012. "Penerapan Metode Data Mining Market Basket Analysis Terhadap Data Penjualan Produk Buku Dengan Menggunakan Algoritma Apriori dan Frequent Pattern Growth ( Fp-Growth):," Telematika, Vol. 4, No. 1, pp. $118-132$.

[6] X. Yu and H. Wang, 2014, "Improvement of Eclat Algorithm Based on Support in Frequent Itemset Mining," J. Comput., Vol. 9, No. 9, pp. 2116-2123.

[7] G. Sinha and S. M. Ghosh, 2014. "Identification of Best Algorithm in Association Rule Mining Based on Performance," Int. J. Comput. Sci. Mob. Comput., Vol. 3, No. 11, pp. $38-45$.

[8] U. Grag and M. Kaur, 2014, "ECLAT Algorithm for Frequent Itemsets Generation," Int. J. Comput. Syst., Vol. 01, No. 03, pp. 82-84.

[9] Ikhwan, 2015, "Penerapan Data Mining dengan Algoritma Fp-Growth untuk Mendukung Strategi Promosi Pendidikan (Studi Kasus Kampus STMIK Triguna Dharma)," Saintikom, Vol. 14, No. 3, pp. 211-226.

[10] M. Subianto, F. AR, and M. Hijriyana P., 2018, "Pola Peminjaman Buku di Perpustakaan Universitas Syiah Kuala Menggunakan Algoritma Eclat," Berk. Ilmu Perpust. dan Inf., Vol. 14, No. 1, p. 35. 